\title{
Montelukast versus inhaled mometasone for treatment of otitis media with effusion in children: A randomized controlled trial
}

\author{
Mohammad Bagher Rahmati ${ }^{1}$, Fatemeh Safdarian ${ }^{2}$, Babak Shiroui ${ }^{3}$, Shahram Zare ${ }^{4}$, Naser Sadeghi ${ }^{5}$
}

${ }^{1}$ Associate Professor of Pediatric Infectious Disease, Clinical Research Development Center of Children Hospital, Hormozgan University of Medical Sciences, Bandar Abbas, Iran

${ }^{2}$ Assistant Professor, Department of Pediatrics, Clinical Research Development Center of Children Hospital, Hormozgan University of Medical Sciences, Bandar Abbas, Iran

${ }^{3}$ Pediatrician ,Clinical Research Development Center Of Children Hospital, Hormozgan University of Medical Sciences, Bandar Abbas, Iran

${ }^{4}$ Ph.D. of Statistics, Professor, Hormozgan University of Medical Sciences, Bandar Abbas, Iran

${ }^{5}$ M.D. of Otolaryngology, Assistant Professor, Hormozgan University of Medical Sciences, Bandar Abbas, Iran

\section{Type of article: Original}

\begin{abstract}
Background: Otitis media is one of the most common infections among children and is a complication in about $30 \%$ of common colds. The most common complication of acute otitis media is otitis media with effusion. Some studies have reported the effects of montelukast and mometasone nasal spray in treatment of otitis media with effusion. However, current information is inadequate in this issue.

Objective: To compare the effectiveness of montelukast and mometasone nasal spray in treatment of otitis media with effusion in children attending Koodakan hospital in Bandar Abbas, Iran.

Methods: This randomized controlled trial was done on 2- to 6-year-old children attending Koodakan Hospital in Bandar Abbas, southern Iran, in 2014. Patients were divided into three groups of montelukast, mometasone, and control group. Audiometry was done for all patients at baseline and four weeks after treatment. Patients were compared for treatment results. Data were analyzed using SPSS 21.0 software.

Results: A total of 143 children were included in the study. Mean age of the participants were $44.64 \pm 18.03$ months. There was no significant difference in treatment results in different treatment groups ( $p>0.05$ ).

Conclusion: Mometasone and montelukast are not effective and not recommended in treatment of otitis media with effusion in children. More studies are needed in this regard.

Trial registration: This study is registered at ClinicalTrials.gov with ClinicalTrials.gov Identifier: NCT02541760.

Funding: The authors received financial support for this research from Hormozgan University of Medical Sciences.

Keywords: Mometasone, Montelukast, Otitis media, Effusion

\section{Introduction \\ 1.1. Background}

Otitis media is among the most common infections in children, and about $30 \%$ of common colds lead to otitis media (1). The most common complication of otitis media is otitis media with effusion (OME), which continues for four weeks in $40 \%$ and continues for three months in $10 \%$ of the patients after acute otitis media. Different treatment strategies are reported for OME, including pharmacological and surgical treatments (2-8). The results of trials on effectiveness of pharmacological treatments of OME are inconsistent (9-13).
\end{abstract}

\section{Corresponding author:}

Dr. Babak Shiroui, Clinical Research Development Center of Children Hospital, Hormozgan University of Medical Sciences, Bandar Abbas, Iran. Tel: +98.9173650284, Email: bshiroui@yahoo.com

Received: July 14, 2016, Accepted: September 05, 2015, Published: July 2017

iThenticate screening: XXX, English editing: January 30, 2017, Quality control: May 17, 2017

(C) 2017 The Authors. This is an open access article under the terms of the Creative Commons Attribution-NonCommercialNoDerivs License, which permits use and distribution in any medium, provided the original work is properly cited, the use is non-commercial and no modifications or adaptations are made. 


\subsection{Statement of problem}

Montelukast is a leukotriene antagonist, which is used in children (11). In OME, several medications are recommended, including antibiotics, antihistamines, and inhaled and oral corticosteroids, but the treatment response is controversial $(9,10,14,15)$. The efficacy of these medications in treatment of OME is limited, and the surgical treatment of tube insertion in tympan is associated with stress and needs anesthesia (16). The results of studies about the efficacy of monteleukast in management of OME are controversial (11, 17-20). Some researchers have reported its efficacy in treatment of OME. Others have reported no efficacy in comparison with the placebo group.

\subsection{Objectives}

The general objective of the study was to compare the efficacy of montelukast and inhaled mometason in treatment OME in 2- to 6-year-old children attending Koodakan Hospital in Bandar Abbas.

\section{Material and Methods}

\subsection{Study design and setting}

This study was a randomized controlled trial, which was done in the Koodakan Hospital in Bandar Abbas in 2014. This hospital is the main educational pediatric hospital in Hormozgan province, which is located in southern Iran.

\subsection{Study population and samples}

The study population consisted of 2- to 6-year-old children attending Koodakan Hospital in 2014. A total of 143 children were randomly selected to participate in the study. Patients were assigned into three groups and were followed. A flow diagram of the children in this study is shown in Figure 1.

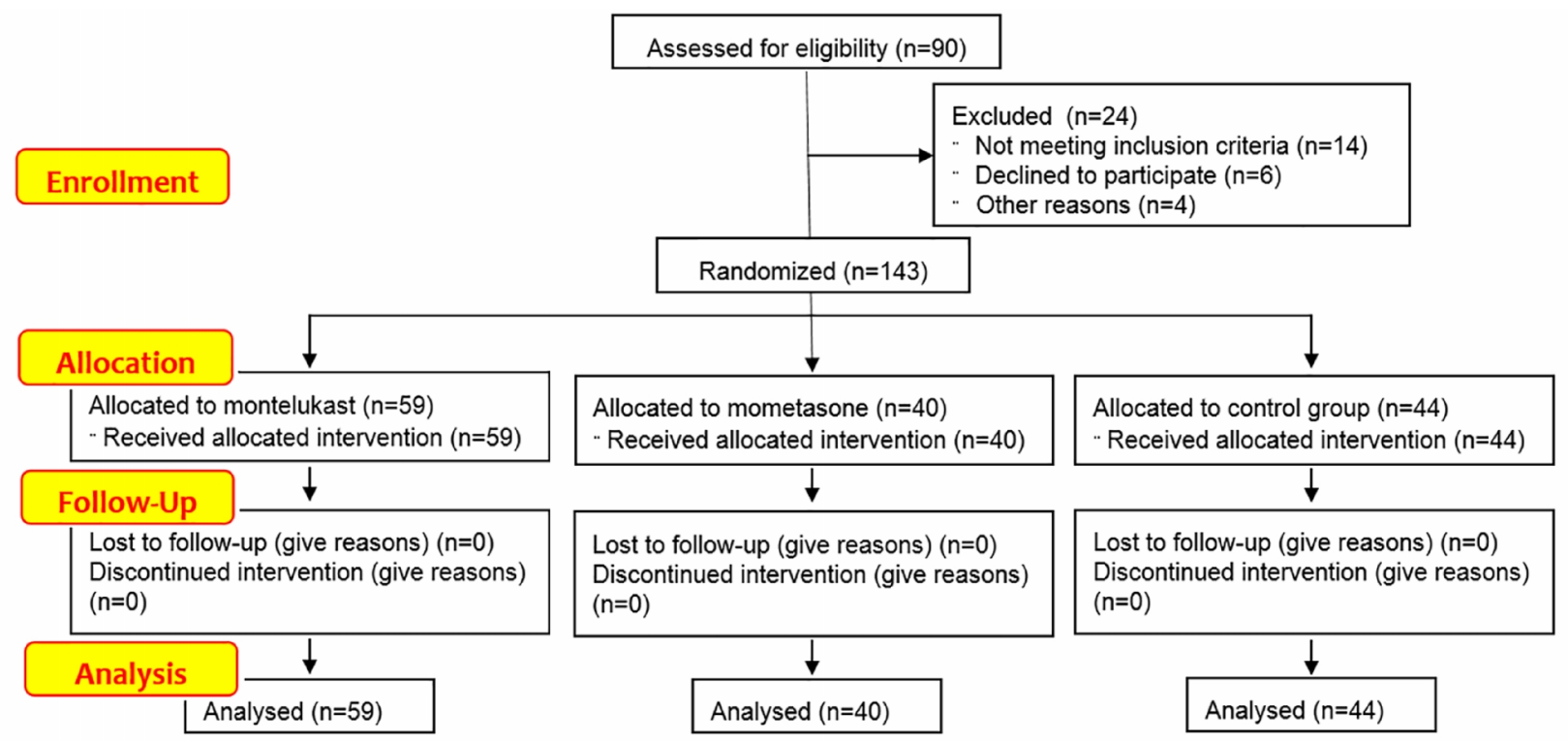

Figure 1. Flow diagram of the children enrolled in the study

\subsection{Inclusion and exclusion criteria}

The inclusion criteria in this study were 1) children between 2 to 6 years old; 2) definite diagnosis of OME with symptoms and examination. Patients were excluded from the study if they had one of the following criteria: 1) currently using corticosteroids or prophylactic montelukast; 2) chronic pulmonary or cardiac diseases or immune deficiency; 3) allergic rhinitis; 4) hypersensitivity to montelukast or corticosteroids; 5) avoidance of parents to fill the written informed consent.

\subsection{Randomization and intervention}

Participants were randomly assigned into three groups. The first group received $4 \mathrm{ml}$ montelukast daily for one month, and the second group received inhaled mometasone: one puff in each side of nose for one month. The third group received no treatment. 


\subsection{Study outcomes}

All patients had undergone tympanometry at the start of study and after one month to confirm the OME and to evaluate the response to treatment. Patients in each group were divided into complete improvement, partial improvement, and no improvement patients.

\subsection{Data collection tools}

Data were collected using a checklist, which included the child's general information and tympanometry, and was completed by the parents. All patients were evaluated by a physician for assessment of treatment response after one month, and the data were recorded.

\subsection{Ethics}

One of the treatments of OME is waiting treatment. Therefore, receiving no medication in the control group is not unethical. The study is confirmed by the ethics committee of Hormozgan University of Medical Sciences. The participants' information was kept confidential.

\subsection{Statistical analysis}

Data was analyzed using IBM( SPSS C Statistics version 21 (IBM@ Corp., Armonk, NY, USA). For data analysis, descriptive statistics and chi-square and independent samples t-test were used. P-value less than 0.05 was assumed to be significant.

\section{Results}

\subsection{Descriptive statistics and baseline characteristics}

We studied 143 children in this study. Among them, 87 (60.8\%) were male and $57(39.2 \%)$ were female. Mean age of study participants was $44.64 \pm 18.03$ months. OME was reported to be unilateral in $85(59.4 \%)$ and bilateral in 58 $(40.6 \%)$ of the study participants. The baseline characteristics of children in three groups are summarized in Table 1. As shown in this table, the patients had similar baseline characteristics. The age of the patients in inhaled mometason was slightly higher in comparison with montelukast and the control group.

Table 1. Baseline characteristics of the study participants

\begin{tabular}{|l|l|l|l|l|}
\hline Variables & & Montelukast & Inhaled mometasone & Control group \\
\hline Gender; $\mathrm{n}(\%)$ & Male & $32(54.2 \%)$ & $24(60 \%)$ & $31(70.5 \%)$ \\
\cline { 3 - 6 } & Female & $27(45.8 \%)$ & $16(40 \%)$ & $13(29.5 \%)$ \\
\hline Age (months); Mean (SD) & & $43.05 \pm 19.08$ & $50.70 \pm 17.58$ & $41.27 \pm 15.90$ \\
\hline Unilateral or bilateral; n (\%) & Unilateral & $35(59.3 \%)$ & $23(57.5 \%)$ & $27(61.4 \%)$ \\
\cline { 2 - 6 } & Bilateral & $24(40.7 \%)$ & $17(42.5 \%)$ & $17(38.6 \%)$ \\
\hline
\end{tabular}

\subsection{Treatment response}

Based on results of the chi-square test, three groups have no significant difference in treatment response. Details are shown in Table 2. As shown in Table 2, complete improvement was reported in $76.3 \%, 82.5 \%$, and $70.5 \%$ in montelukast, mometasone, and the control group, respectively.

Table 2. Comparison of treatment response in study participants

\begin{tabular}{|l|l|l|l|l|}
\hline Treatment response & Montelukast & Mometasone & Control & p-value \\
\hline Complete improvement & $45(76.3 \%)$ & $33(82.5 \%)$ & $31(70.5 \%)$ & \multirow{2}{*}{0.416} \\
\cline { 1 - 4 } Relative improvement & $9(15.3 \%)$ & $4(10 \%)$ & $11(25 \%)$ & \\
\cline { 1 - 4 } No response & $5(8.5 \%)$ & $3(7.5 \%)$ & $2(4.5 \%)$ & \\
\hline
\end{tabular}

\section{Discussion}

OME is one of the common problems in children (5). Although OME can be asymptomatic, without treatment it may lead to auditory problems or learning disorders. Therefore, early treatment is recommended. Despite this, current available medications have unacceptable efficacies, and controversy exists in different research results. In this study, we have reported no effectiveness for montelukast or mometasone for treatment of OME in children. Although Aynali et al. have reported the efficacy of montelukast in treatment of OME (18), their study was done in rats and, therefore, is different from our study. Bhargava et al. have reported the efficacy of mometasone in treatment of OME in children. Their study was done on children between 2 to 12 years old, but our study was done 
on children 2 to 6 years old. Also we had evaluated the children after one month, but Bhargava et al. evaluated their patients at baseline and after 8 and 24 weeks (10). Combs et al. reported the efficacy of montelukast in OME, which is different from our study, but their study population consisted of 2 to 12 year old children, which was different from our study (20). Similar results about the efficacy of montelukast in treatment of OME were reported by Ertugay et al (17). They reported the efficacy of montelukast alone or in combination with levocitirizine in treatment of OME. Their sample size were higher in comparison to our study. Some studies such as the study by Ucar et al confirms our findings that montelukast is not effective in treatment of OME (11). The study by Ucar et al is done on rats. More studies in human are needed to confirm or reject our results. One important issue in assessment of treatment response in duration of treatment. In this study we have followed the patients for one month. Longer periods of follow up may be needed to receive positive treatment response.

\section{Conclusions}

Our findings showed that montelukast and inhaled mometasone have no benefits on treatment of OME on a period of one months. We do not recommend using mometasone and montelukast in treatment of OME. However, more studies are needed to confirm our study results. Longer period of treatments may be needed in these patients.

\section{Acknowledgments:}

The study is the results of thesis carried out by Babak Shiruyi for fulfillment of requirements required for acquiring degree of doctorate of medicine in pediatrics diseases. The authors want to thank to Hormozgan University of Medical Sciences personnel and directors for their help and support.

\section{Trial registration:}

This study is registered at ClinicalTrials.gov with ClinicalTrials.gov Identifier: NCT02541760.

\section{Funding:}

The authors received financial support for this research from Hormozgan University of Medical Sciences.

\section{Conflict of Interest:}

There is no conflict of interest to be declared.

\section{Authors' contributions:}

All authors contributed to this project and article equally. All authors read and approved the final manuscript.

\section{References:}

1) Simasek M, Blandino DA. Treatment of the common cold. Am Fam Physician. 2007; 75(4): 515-20. PMID: 17323712.

2) Coker TR, Chan LS, Newberry SJ, Limbos MA, Suttorp MJ, Shekelle PG, et al. Diagnosis, microbial epidemiology, and antibiotic treatment of acute otitis media in children: a systematic review. JAMA. 2010; 304(19): 2161-9. doi: 10.1001/jama.2010.1651. PMID: 21081729.

3) Casselbrant ML, Mandel EM, Rockette HE, Kurs-Lasky M, Fall PA, Bluestone CD. Adenoidectomy for otitis media with effusion in 2-3-year-old children. Int J Pediatr Otorhinolaryngol. 2009; 73(12): 1718-24. doi: 10.1016/j.ijporl.2009.09.007. PMID: 19819563, PMCID: PMC2787742.

4) Thomas CL, Simpson S, Butler CC, van der Voort JH. Oral or topical nasal steroids for hearing loss associated with otitis media with effusion in children. Cochrane Database Syst Rev. 2006; (3): CD001935. doi: 10.1002/14651858.CD001935.pub2. PMID: 16855980.

5) American Academy of Family P, American Academy of O-H, Neck S, American Academy of Pediatrics Subcommittee on Otitis Media With E. Otitis media with effusion. Pediatrics. 2004; 113(5): 1412-29. PMID: 15121966.

6) Mandel EM, Casselbrant ML, Rockette HE, Fireman P, Kurs-Lasky M, Bluestone CD. Systemic steroid for chronic otitis media with effusion in children. Pediatrics. 2002; 110(6): 1071-80. PMID: 12456902.

7) Fireman P. Effect of early or delayed insertion of tympanostomy tubes. Curr Allergy Asthma Rep. 2002; 2(4): 295-6. PMID: 12044263.

8) Butler CC, Van Der Voort JH. Oral or topical nasal steroids for hearing loss associated with otitis media with effusion in children. Cochrane Database Syst Rev. 2002; (4): CD001935. doi: 10.1002/14651858.CD001935. PMID: 12519563. 
9) Tapiainen T, Kujala T, Renko M, Koivunen P, Kontiokari T, Kristo A, et al. Effect of antimicrobial treatment of acute otitis media on the daily disappearance of middle ear effusion: a placebo-controlled trial. JAMA Pediatr. 2014; 168(7): 635-41. doi: 10.1001/jamapediatrics.2013.5311. PMID: 24797294.

10) Bhargava R, Chakravarti A. A double-blind randomized placebo-controlled trial of topical intranasal mometasone furoate nasal spray in children of adenoidal hypertrophy with otitis media with effusion. Am J Otolaryngol. 2014; 35(6): 766-70. doi: 10.1016/j.amjoto.2014.06.006. PMID: 25151658.

11) Ucar S, Huseynov T, Coban M, Sarioglu S, Serbetcioglu B, Yalcin AD. Montelukast is as effective as penicillin in treatment of acute otitis media: an experimental rat study. Med Sci Monit Basic Res. 2013; 19: 246-52. doi: 10.12659/MSMBR.889474. PMID: 24048018, PMCID: PMC3808231.

12) Simpson SA, Lewis R, van der Voort J, Butler CC. Oral or topical nasal steroids for hearing loss associated with otitis media with effusion in children. Cochrane Database Syst Rev. 2011; (5): CD001935. doi: 10.1002/14651858.CD001935.pub3. PMID: 21563132.

13) Leach AJ, Morris PS, Mathews JD, Chronic Otitis Media Intervention Trial - One g. Compared to placebo, long-term antibiotics resolve otitis media with effusion (OME) and prevent acute otitis media with perforation (AOMwiP) in a high-risk population: a randomized controlled trial. BMC Pediatr. 2008; 8: 23. doi: 10.1186/1471-2431-8-23. PMID: 18513453, PMCID: PMC2443129.

14) Daniel M. Antibiotics for otitis media with effusion in children. Clin Otolaryngol. 2013; 38(1): 56-7. doi: 10.1111/coa.12069. PMID: 23418968.

15) Van Zon A, van der Heijden GJ, van Dongen TM, Burton MJ, Schilder AG. Antibiotics for otitis media with effusion in children. Cochrane Database Syst Rev. 2012; 9: CD009163. doi: 10.1002/14651858.CD009163.pub2. PMID: 22972136.

16) Wallace IF, Berkman ND, Lohr KN, Harrison MF, Kimple AJ, Steiner MJ. Surgical treatments for otitis media with effusion: a systematic review. Pediatrics. 2014; 133(2): 296-311. doi: 10.1542/peds.2013-3228. PMID: 24394689.

17) Ertugay CK, Cingi C, Yaz A, San T, Ulusoy S, Erdogmus N, et al. Effect of combination of montelukast and levocetirizine on otitis media with effusion: a prospective, placebo-controlled trial. Acta Otolaryngol. 2013; 133(12): 1266-72. doi: 10.3109/00016489.2013.824113. PMID: 23972320.

18) Aynali G, Yariktas M, Yasan H, Karahan N, Baspinar S, Tuz M, et al. The effects of methylprednisolone, montelukast and indomethacine in experimental otitis media with effusion. Int J Pediatr Otorhinolaryngol. 2011; 75(1): 15-9. doi: 10.1016/j.ijporl.2010.09.024. PMID: 21036406.

19) Schoem SR, Willard A, Combs JT. A prospective, randomized, placebo-controlled, double-blind study of montelukast's effect on persistent middle ear effusion. Ear Nose Throat J. 2010; 89(9): 434-7. PMID: 20859868.

20) Combs JT. The effect of montelukast sodium on the duration of effusion of otitis media. Clin Pediatr (Phila). 2004; 43(6): 529-33. PMID: 15248005. 